\title{
Fatores associados ao abandono do tratamento de álcool e outras drogas em
}

\section{moradores de rua}

\author{
Factors associated with abandonment of alcohol and other drugs treatment in street residents \\ Factores asociados con abandono de alcohol y otras drogas en residentes de la calle
}

Recebido: 23/11/2021 | Revisado: 27/11/2021 | Aceito: 29/11/2021 | Publicado: 11/12/2021

Larissa Eduarda Flauzino do Nascimento
ORCID: https://orcid.org/0000-0003-0897-1146
Faculdade Interamericana de Porto Velho, Brasil
E-mail: larissa.eduarda.flauzino@gmail.com
Juliana Maria Lucena Fernandes Dantas
ORCID: https://orcid.org/0000-0003-2570-1711
Faculdade Interamericana de Porto Velho, Brasil
E-mail: juliana2_pvh@ hotmail.com
Ivana Annely Cortez da Fonseca
ORCID: https://orcid.org/0000-0001-6598-5945
Faculdade Interamericana de Porto Velho, Brasil
E-mail: ivana.fonseca@ uniron.edu.br

\begin{abstract}
Resumo
O estudo teve como objetivo avaliar os fatores associados ao abandono do tratamento de álcool e outras drogas em moradores de rua de Porto Velho/RO. Para a realização optou-se por uma pesquisa de campo investigatória descritiva sustentada por abordagem qualitativa. A pesquisa foi realizada juntamente com a equipe do Consultório na Rua (ECR) nos seus atendimentos, com 12 moradores de rua de acordo com os critérios de inclusão e exclusão, com uso da técnica entrevista com roteiro semiestruturado, considerando os aspectos éticos e legais da pesquisa determinados pela Resolução 466/12 do Conselho Nacional de Saúde/Ministério da Saúde. Os dados foram transcritos na íntegra para análise, respeitando o sigilo das informações. Mediante as falas e diante da observação empírica dos relatos ficou especificados três categorias temáticas, sendo elas: Sentimentos Vivenciados e o Direito de Cidadania, Lacunas no Contexto Familiar e o Uso de Álcool e Outras Drogas e o Vício e o Prejuízo no Abandono do Tratamento. Observouse a importância da ECR como simplificadora no acesso desta população aos serviços de saúde. Evidenciou-se também o baixo investimento pelas políticas públicas no programa, ao qual salientamos a necessidade de melhorias e investimento adequado, visto que este está diretamente ligado aos serviços de saúde ofertados para os moradores de rua.
\end{abstract}

Palavras-chave: Acesso à informação de saúde; Pessoas em situação de rua; Usuário de drogas; Humanização da assistência.

\begin{abstract}
The study aimed to evaluate the factors associated with the abandonment of alcohol and other drug treatment among homeless people in Porto Velho/RO. For the realization, we opted for a descriptive investigative field research supported by a qualitative approach. The research was carried out together with the Street Clinic (ECR) team in their services, with 12 homeless people according to the inclusion and exclusion criteria, using the interview technique with a semi-structured script, considering the ethical and legal aspects of the research determined by Resolution 466/12 of the National Health Council / Ministry of Health. The data were transcribed in full for analysis, respecting the confidentiality of the information. Through the speeches and in view of the empirical observation of the reports, three thematic categories were selected, namely: Experienced Feelings and the Right to Citizenship, Gaps in the Family Context and the Use of Alcohol and Other Drugs, and Addiction and Damage to Treatment Abandonment. The importance of the RCT as a facilitator in the access of this population to health services was observed. The low investment by public policies in the program was also evidenced, which highlights the need for improvements and adequate investment, as this is directly linked to the health services offered to homeless people.
\end{abstract}

Keywords: Access to health information; Homeless people; Drug user; Humanization of care.

\section{Resumen}

El estudio tuvo como objetivo evaluar los factores asociados con el abandono del alcohol y otros tratamientos por drogas entre las personas sin hogar en Porto Velho / RO. Para la realización, se optó por una investigación de campo descriptiva sustentada en un enfoque cualitativo. La investigación se realizó en conjunto con el equipo de Street Clinic 
(ECR) en sus servicios, con 12 personas sin hogar según los criterios de inclusión y exclusión, utilizando la técnica de entrevista con guión semiestructurado, considerando los aspectos éticos y legales de la investigación. determinado por Resolución 466/12 del Consejo Nacional de Salud / Ministerio de Salud, los datos fueron transcritos íntegramente para su análisis, respetando la confidencialidad de la información. A través de los discursos y en vista de la observación empírica de los informes, se seleccionaron tres categorías temáticas, a saber: Sentimientos vividos y el derecho a la ciudadanía, Lagunas en el contexto familiar y el uso de alcohol y otras drogas, y Adicción y daño al tratamiento. Abandono. Se observó la importancia del ECA como facilitador en el acceso de esta población a los servicios de salud. También se evidenció la baja inversión de las políticas públicas en el programa, lo que resalta la necesidad de mejoras y una adecuada inversión, ya que esta está directamente vinculada a los servicios de salud que se ofrecen a las personas sin hogar.

Palabras clave: Acceso a información sanitaria; Gente sin hogar; Consumidor de drogas; Humanización del cuidado.

\section{Introdução}

O uso abusivo de álcool e outras drogas se transformou em um grave problema de saúde pública no Brasil e no mundo. A batalha contra essa problemática constitui-se uma demanda mundial, tendo em vista que a Organização Mundial de Saúde (OMS) assegura que 10\% das populações de centros urbanos de diversas partes do mundo realizam um uso abusivo de substâncias psicoativas, fato este sem relação com idade, orientação sexual, escolaridade e classe social (Filho, 2017).

A vivência em situação de rua e o consumo de drogas são fatos comuns à evolução histórica da humanidade. Encontrar-se nesta situação e/ou praticar o consumo de drogas são ações mediadas por preconceitos e paradigmas que dirigem para um afastamento da sociedade. Entretanto, nem sempre ambas as condutas estejam correlacionadas, o cenário desses moradores torna-se conveniente para fornecer ou potencializar o uso de substâncias psicoativas (SPA), uma vez que tal utilização pode representar um método de encontros comunitários e de pertencimento ao grupo de rua (Campos et al., 2019).

Esse mesmo grupo é tradicionalmente marcado por um regime de exclusão da assistência de serviços públicos de saúde, onde a sua permanência manifesta um notório desconforto tanto para os profissionais de saúde quanto para os outros usuários, fazendo assim com que os seus acessos aos atendimentos de saúde sejam privados, quando muito, apenas são atendidos nas emergências (Hamada et al, 2018).

Dificilmente os serviços de saúde conseguem visualizar a heterogeneidade de pessoas que realizam o consumo de drogas, assim como de pessoas em situação de rua, ocasionando assim exclusão social e problemas para a saúde mental e física desses indivíduos (Campos et al., 2019).

Tanto a discriminação quanto a ausência de confiança nas unidades e a fragilidade de elos com essa população acabam por complicar a busca por assistência de saúde por parte dos moradores de rua (Giovanella et al., 2018).

Diante disto, os profissionais que atuam nos atendimentos voltados para esses indivíduos sejam no Consultório na Rua ou nos demais serviços de saúde devem ter respeito e empatia para criar vínculo com os moradores (Venturi, 2021).

A motivação para cessar o uso de substâncias psicoativas varia de pessoa para pessoa, e se manifesta de forma incerta, variando em diferentes momentos do seu caminho. As formas atuais de tratamento apontam a motivação como um fator relevante para as pessoas escolherem se tratar, com isso as abordagens terapêuticas devem apresentar recursos que favoreçam esse sentimento, reduzam as resistências e assegurem um vínculo na relação com o profissional e a instituição. Como exemplo de métodos que favoreçam a motivação, destaca-se a viabilidade de recuperar laços familiares, em geral suficientemente enfraquecidos ou desfeitos em decorrência da utilização das drogas, isso irá propiciar a família ver que o indivíduo está se esforçando para interromper ou minimizar o uso de drogas e poderá se unir para apoiá-lo nessa decisão, aumentando e fortalecendo, assim, o seu comprometimento (Brasil, 2012).

Uma das teorias para o baixo acesso da população usuária de drogas às ofertas de tratamento se dá ao padrão adotado pelo sistema político brasileiro para enfrentar a temática do uso de drogas, sistema este que é centrado no proibicionismo e frisado por coibição, repressão, criminalidade e psiquiatrização. Entretanto, com o passar dos anos esse 
modelo político sofreu mudanças significativas que passaram a reconhecer as drogas como uma temática de calamidade social e não somente como uma questão punível no âmbito da justiça-penal, isso propiciou a criação de políticas públicas em saúde visando a prevenção, o tratamento e a reinserção do usuário de drogas na sociedade (Rossi \& Tucci, 2020).

Diante do exposto este estudo se propõe a responder a seguinte questão norteadora: Quais os fatores associados ao abandono do tratamento de Álcool e outras Drogas na população em situação de Rua em Porto Velho-RO?

Neste sentido o objetivo desta pesquisa é compreender os principais motivos que levaram os moradores de rua ao abandono do tratamento de Álcool e outras drogas na cidade de Porto Velho-RO.

\section{Metodologia}

Tratou-se de uma pesquisa de campo investigatória-descritiva, sustentada por abordagem qualitativa através do uso de questionário com questões abertas. Tendo como foco central a população em situação de rua e o abandono do tratamento para Álcool e outras Drogas.

O método qualitativo de pesquisa é compreendido como aquele que se relaciona com a subjetividade e realidade social, compreendido através da história, dos motivos, crenças, valores, ensinamentos, significados e atitudes dos atores sociais (Taquette \& Minayo, 2016).

Para a seleção amostral, foi utilizada a amostragem por conveniência do tipo não probabilística, dos quais foram convidados a participar de maneira voluntária do estudo um número total de 12 moradores de rua através dos critérios de inclusão e exclusão. A amostra inicial seria composta por 20 sujeitos, entretanto justifica-se a perda amostral por 3 fatores sendo estes: à recusa do participante a participar da entrevista, está sobre o efeito da substância psicoativa no momento da abordagem e nunca ter realizado tratamento para álcool ou outras drogas.

Para o desenvolvimento da pesquisa foram contempladas as disposições da Resolução 466/12 do Conselho Nacional de Saúde/Ministério Saúde, que dispõe sobre as pesquisas envolvendo seres humanos. A pesquisa deu início após a autorização prévia do Núcleo Gestor de Educação Permanente - NUGEP em Julho/2021 e aprovação do Comitê de Ética e Pesquisa (CEP) da União Educacional do Norte Ltda - UNINORTE, em 05 de Outubro de 2021, com o parecer com nº 5.067.464 e CAAE: 51994821.1 .0000 .8028 .

Após a autorização, as pesquisadoras direcionaram-se para a sede do Consultório na Rua, onde houve um contato breve com a equipe multiprofissional, no intuito de alinhar a melhor oportunidade para localizar os moradores de rua e realizar a coleta de dados.

Mediante isto, definiu-se então que o momento oportuno seria nos atendimentos do Consultório na Rua, onde neste período eles realizam o contato direto com os sujeitos da pesquisa. Após deparar-se com os moradores de rua, os que aceitaram participar voluntariamente da pesquisa receberam informações a respeito do estudo e foram informados que todos os participantes iriam ter o seu sigilo garantido e em hipótese alguma seriam identificados.

Os critérios de inclusão para a participação do morador de rua na pesquisa foram ter sido atendido pela equipe do Consultório na Rua, ter realizado e abandonado o tratamento para uso abusivo de Álcool e outras drogas, possuir idade igual ou superior a 18 anos e assinar o Termo de Consentimento Livre e Esclarecido (TCLE).

Foram excluídos da pesquisa, moradores de rua que se negaram a responder as perguntas da entrevista, que apresentaram sinais aparentes de efeito de uso de qualquer substância psicoativa no momento da abordagem para coleta de dados e alterações cognitivas que dificultaram a realização da entrevista. 
A entrevista foi realizada mediante roteiro semiestruturado contendo 07 perguntas elaboradas pelas pesquisadoras, atrelado a isso houve também a utilização de um dispositivo móvel para gravar, de maneira individual, a fala dos participantes e depois transcrevê-las na íntegra.

Ressalta-se que, os participantes foram identificados pelas seguintes siglas M1, M2, M3, M4, e assim por diante, no qual $\mathrm{M}$ se refere ao morador e o número arábico corresponde à ordem em que a entrevista foi realizada de modo a preservar o anonimato dos participantes.

\section{Resultados e Discussões}

A amostra final foi composta por 12 moradores de rua que realizaram o tratamento para Álcool e outras drogas e abandonaram, no Munícipio de Porto Velho - RO.

As principais informações referentes a caracterização dos moradores de rua que já abandonaram o tratamento de álcool e outras drogas são referentes a faixa etária que está entre 18 a 63 anos, com predominância do sexo masculino. O álcool é a substância mais utilizada nas ruas devido a sua facilidade de acesso por se tratar de uma substância psicoativa lícita e a frequência de abandono do tratamento foi superior a duas vezes.

O perfil dos entrevistados e códigos de identificação encontram-se no Quadro 1.

Quadro 1 - Distribuição do perfil sociodemográfico dos moradores participantes da pesquisa, atendidos pela equipe do Consultório na Rua em Porto Velho (RO), 2021.

\begin{tabular}{|l|l|l|c|c|}
\hline & & & & \\
\hline
\end{tabular}

Fonte: Nascimento e Dantas (2021).

A partir da observação empírica dos relatos, por meio dos dados convergentes comparamos os principais motivos para o abandono do tratamento de álcool e outras drogas em moradores de rua. Após exaustiva análise das falas dos participantes da pesquisa, emergiram três grupos temáticos, a saber: Sentimentos Vivenciados e o Direito de Cidadania, Lacunas no Contexto Familiar e o Uso de Álcool e Outras Drogas e O Vício e o Prejuízo no Abandono do Tratamento. 


\section{Sentimentos Vivenciados e o Direito de Cidadania}

$\mathrm{O}$ primeiro conceito de cidadania surgiu na cidade-estado ateniense. Este simbolizava o pertencimento à cidade $\mathrm{e}$ seu conjunto político. Atualmente o termo cidadania engloba tópicos políticos e jurídicos que permeiam em todo o território nacional e denomina-se "democracia", gerando assim um pertencimento ao estado (Magnin, 2021).

Entre os preceitos essenciais a constituição federal de $1988 \mathrm{em}$ seu artigo $1^{\circ}$ inciso III traz a defesa da dignidade, importância e o valor do ser humano em sociedade, evidenciando que para viver com dignidade a pessoa necessita possuir uma moradia, alimentação, acesso a assistência em saúde, oportunidades de trabalho, acesso à momentos de lazer, vestimenta, calçados, entre outros (Santana \& Mungo, 2021).

Sendo assim, a cidadania não se resume apenas ao voto, mas sim em um conjunto de direitos sociais e econômicos, permitindo assim a integração do indivíduo na vida coletiva do Estado (Lima et al., 2017).

Durante a coleta de dados, foi abordado a questão do ser cidadão, se estes moradores se consideravam cidadãos perante a sociedade, e predominantemente estes relataram o sentimento de exclusão, rejeição e a ausência de cidadania, conforme falas a seguir:

\section{“[...] Cidadão é alguém visto né? Ah nem sei, nem sei, eu acho que não [...]” (M8).}

“[...] Como um delinquente, como um animal assim na margem da sociedade devido a essas circunstâncias, porque a pessoa que usa droga não tá dentro da lei, ta fora da lei, então se eu to usando droga eu to fora da lei e sou considerado no mínimo um criminoso [...]" (M10).

“[...] A sociedade devia olhar mais pra nós que somos seres humanos entendeu? Mas, no entanto, somos desprezados como um cachorro, ou até pior do que um cachorro [...]” (M4).

O morador não tem conhecimento sobre a sua condição de cidadão, as suas obrigações e os seus direitos na sociedade, não tem acesso as informações, portanto não usufrui da posição de cidadão e sobrevive nas ruas idealizando os seus próprios conceitos sobre valor social que inevitavelmente não será o mesmo vivido pela maioria dos integrantes da sociedade. Na medida que aumenta o tempo que esse morador vive nas ruas cresce também a desfiguração do conhecimento de ser humano, tornando assim mais difícil a inclusão social (Thome, 2019).

A extinção do direito à cidadania acarreta vários problemas aos moradores de rua principalmente no âmbito do acesso aos serviços de saúde, a falta de compromisso civil torna-os invisíveis (Pio et al., 2020).

\section{Lacunas no Contexto Familiar e o Uso de Álcool e Outras Drogas}

Os vínculos familiares são essenciais para o desenvolvimento do ser humano em comunidade. O convívio familiar é a origem da formação e capacitação dos integrantes para sua inserção na sociedade, desta forma a família torna-se a principal orientação para a prática das relações sociais. Os níveis de afetividade com os membros familiares interferem tanto na formação dos valores individuais quanto na percepção do entendimento da sua relevância e projeção em sociedade (Ceolin \& Carmona, 2020).

A interrupção dos laços familiares tem um peso importante quando se fala de fatores para as pessoas viverem em situação de rua. É observado que esses laços têm muita ligação com o uso de substâncias psicoativas, tonando tanto fator de 
vulnerabilidade quanto de refúgio. Quando esse elo familiar se torna divergente, como por exemplo com desavenças constantes ele se transforma em uma ameaça criando o distanciamento de seus integrantes (Mota et al., 2019).

Sendo assim, as relações familiares são a base na formação do indivíduo enquanto criança e adolescente e influenciam de forma significativa na construção de experiências, aprendizados e lembranças, durante diversas entrevistas tornou-se evidente que os moradores de rua possuíam várias lacunas no contexto familiar que contribuíram para o início do uso de álcool ou outras drogas, seja por exemplo de um membro familiar, ou até mesmo por maus tratos, rejeição e abandono que consequentemente levou a fuga de seus lares e a ida para as ruas, evidenciamos aqui algumas falas:

“[...] ah foi curiosidade, meu cunhado tava usando lá e eu fui [...]” (M8)

“[...] comecei com o álcool, o álcool é a primeira porta de entrada no meio da família, cervejinha no natal e depois a cocaína no sábado e depois virou rotina [...]" (M7).

“[...] tinha meus pais que bebia e eu não gostava que eles bebia, que quando meu cunhado chegava da fazenda ele comprava as coisas em casa mas depois colocava todos os amigos dentro da porta de casa e começava a beber álcool e aí tinha vez que ele discutia com meu pai e eu não gostava, as vezes ele queria brigar com a minha irmã aí eu enfrentei ele e pronto, mas aí eu não achava que hoje eu taria vivendo no álcool, antigamente eu tomava cerveja ai depois de tudo isso aí eu só to bebendo bebida forte a cachaça [...]”" (M5).

"[...] porque eu briguei com a minha mãe entendeu, aí um abençoado me chamou pra usar, e assim por curiosidade eu fui e to até hoje, porque desde os doze anos a minha mãe me batia muito, eu sempre era rejeitada entendeu? Principalmente pela minha mãe, que Deus o tenha, assim eu amo ela entendeu, mas eu fiquei revoltada aí eu peguei e sai de casa, eu fui em casa só como visita o que eu aprendi de certo e de errado foi na rua o mundo me ensinou [...]” (M9).

“[...] meu pai sempre bebia umas e me maltratava, falava que eu ia virar bandido que ia ser noiado [...]” (M5).

Oliveira et al. (2020), ressalta que o desenvolvimento da identidade social dessas pessoas é formado através de situações conflituosas com os familiares, e quando em contato com o uso abusivo de substâncias psicoativas traz um novo grupo social ao qual esse indivíduo se identifica gerando assim o sentimento de pertencimento.

Após o início do consumo de álcool ou outras drogas o morador de rua depara-se com outra questão familiar a falta de apoio no tratamento, sendo a falta de confiança a questão principal, evidenciado a seguir:

“[...] eu tenho irmãs aqui eu vou lá elas ficam meio assim apreensiva ainda porque não pode confiar, elas tenta ajudar mas só que só o monetário não adianta [...]” (M7).

“[...] Primeiro é a família né se afasta, primeiro lugar é a família, aí vai perdendo a confiança, minha mãe é do interior, ela ajuda, mas sempre fica com aquela desconfiança, a pulga atrás da orelha que fala [...]” (M8). 
Research, Society and Development, v. 10, n. 16, e178101623826, 2021

(CC BY 4.0) | ISSN 2525-3409 | DOI: http://dx.doi.org/10.33448/rsd-v10i16.23826

O vício em álcool ou drogas é considerado um grave problema de saúde pública, atrelado a isso ressalta-se a importância da família nesse contexto como peça chave para o sucesso do tratamento (Nascimento, 2021).

Segundo Siqueira et al. (2018), a família é a principal responsável por fatores preventivos, protetores e cuidadores no processo de deserção da dependência química.

Os sujeitos que contam com o apoio da família no tratamento se sentem mais incentivados e confiantes, ocasionando assim a diminuição do sentimento de solidão contribuindo significativamente no processo do cuidado (Belotti et al., 2017).

Vale ressaltar, que a dependência química gera graves prejuízos na qualidade de vida tanto dos usuários como de seus familiares (Nascimento, 2021).

\section{O Vício e o Prejuízo no Abandono do Tratamento}

A droga é caracterizada como uma substância que altera a fisiologia do corpo humano, usada com ou sem o objetivo de benefício para a pessoa que faz o uso. Já o vício é o uso obsessivo que acarreta em prejuízos e sofrimento em várias situações para o indivíduo, como, alterações comportamentais, fisiológicas e cognitivas (Toigo, 2021).

Dentre os motivos que causam o abandono do tratamento o vício é uma das principais causas, evidenciado conforme discursos abaixo:

“[...] às vezes eu fico pensando falo rapaz o que que é isso? a gente não se domina, muitas vezes a gente pega o dinheiro fala ah eu vou fazer isso, isso e isso, no outro dia eu to la oh, jogado numa ressaca com vergonha, é isso que me destrói, pow as vezes você tem uma mente tão inteligente pra certas coisas e não consegue vencer um saquinho de pó, uma pedra [...]” (M7).

“[...] é porque a droga fala mais alto, a gente quer um tratamento ai não consegue, vai até lá perto e volta ai encontra um amigo as vezes tu não quer usar droga ai o amigo, não bora lá, não vamo se tratar, não vamo lá rapidão ai é isso que acontece [...]" (M2).

O vício é uma questão de difícil compreensão e acolhimento, tendo em vista que, não se pode submeter uma pessoa ao tratamento sem a sua concessão. O uso das substâncias por diversas vezes é usado como mecanismo de fuga da realidade (Camporesi, 2019).

Sendo assim, o ato voluntário do usuário ingressar nos serviços de saúde voltados ao abandono de substâncias psicoativas, reforça a efetividade da assistência a ser prestada, visto que as internações obrigatórias representam atuar contra o desejo do paciente (Santos et al., 2021).

Entretanto, quando questionados os participantes relataram a ausência da vontade de começar um tratamento e continuar nele, evidenciando que a ação principal de buscar um tratamento deve sempre partir do usuário, conforme exposto a seguir:

“[...] depende muito, muito da pessoa porque não adianta alguém querer me ajudar e eu não querer ou simplesmente ficar aproveitando até certo momento, porque uma hora recai, não tem como esconder [...]”. (M7).

“[...] Falta nós né ter nossa opinião, porque os benefícios tem é mais é nós, acho que o primeiro passo quem tem que dar é nós [...]” (M8). 
Atrelado a isto, deparamos também com diversos serviços de saúde que tem como principal mecanismo o tratamento pautado na abstinência total como o único método de garantir a eficácia do tratamento. Esse modelo de cuidado atrelado as demais barreiras encontradas no acesso aos serviços voltados à população usuária de álcool ou outras drogas, tem contribuído cada vez mais para o abandono do tratamento (Rossi \& Tucci, 2020). Como podemos ver a seguir:

"Se chama abstinência entendeu, porque uns dizem que é até seis meses pra sair do sangue da pessoa, então nesse caso ai eu creio que foi a abstinência” (M4).

Conforme a Política do Ministério da Saúde para a Atenção Integral a Usuários de Álcool e outras drogas a abstinência não pode ser o fator principal do recurso terapêutico, sendo indispensável lidar com as diversas vontades e preferências do paciente, destaca-se aqui a Política Nacional de Redução de Danos que surgiu como uma das novas estratégias do cuidado, todavia ainda não é devidamente abordada na esfera da saúde pública no Brasil (Lopes \& Gonçalves, 2018).

Destaca-se também que dos entrevistados a maior parte realizou o tratamento para álcool ou drogas em casas de apoio ofertadas pela igreja, onde estas predominantemente possuem como foco no tratamento a abstinência total, causando diversas desistências no decorrer do cuidado.

\section{Considerações Finais}

Os resultados obtidos neste estudo possibilitaram a caracterização do perfil dos moradores de rua, sendo eles na faixa etária de 18 a 63 anos com predominância do sexo masculino, foi observado também que o álcool é a substância que prevalece nas ruas, porém, é a porta de entrada para o vício que em sua maior parte evolui para o crack.

Durante as entrevistas foi perceptível que a maioria dos moradores de rua não tinham o ensino fundamental completo e que quanto menor o grau de escolaridade maior foi a dificuldade em se manter um bom diálogo.

Quanto a quantidade de abandono do tratamento a média foi superior a duas vezes para cada morador entrevistado e os principais motivos estão relacionados a ausência de vínculos familiares e a rotina da vida nas ruas, onde o vício predomina sobre o desejo de realizar o tratamento e a abstinência torna o usuário impossibilitado de dar continuidade.

Ressaltamos o papel fundamental da família no apoio ao tratamento, tendo em vista que, os laços familiares são um alicerce essencial para motivar e apoiar o usuário no período de recuperação.

Destaca-se a importância do Consultório na Rua como facilitador para o acesso dos moradores de rua aos serviços de saúde o qual também englobam as questões do tratamento de álcool e drogas. Observou-se durante as entrevistas que os entrevistados se sentem bem acolhidos pela ECR por ser um serviço pouco burocrático e humanizado.

Entretanto, durante visita a UBS Maurício Bustani onde está localizado o Consultório na Rua observamos limitações de investimentos em infraestrutura, equipe e transporte. Observamos também que a equipe não possui registros físicos/digitais dos usuários atendidos pelo programa.

Sendo assim, ressalta-se a necessidade de melhoria e investimento adequado na política pública que engloba o Consultório na Rua, visto que este está diretamente ligado aos serviços de saúde ofertados para os moradores de rua.

Faz-se necessário também, o avanço de pesquisas que tenham como foque a temática abordada neste estudo, uma vez que o morador de rua está por diversas vezes invisível diante do poder público e que o uso abusivo de álcool ou drogas é um fator que cresce cada vez mais na sociedade e acarreta diversos prejuízos na vida do indivíduo. 
Research, Society and Development, v. 10, n. 16, e178101623826, 2021 (CC BY 4.0) | ISSN 2525-3409 | DOI: http://dx.doi.org/10.33448/rsd-v10i16.23826

\section{Referências}

Belotti, M., Fraga, H. L., \& Belotti, L. (2017). Família e atenção psicossocial: o cuidado à pessoa que faz uso abusivo de álcool e outras drogas/Family and psychosocial attention: care for the person with abusive use of alcohol and other drugs. Cadernos Brasileiros de Terapia Ocupacional, 25(3).

Brasil. (2012). Manual sobre o cuidado à saúde junto a população em situação de rua.

Camporesi, B. M. D. A. (2019). Moradores de rua: uma sociedade em descobrimento.

Campos, L. C. M., de Oliveira, J. F., Porcino, C., Reale, M. J. D. O. U., Santos, M. V. S., \& de Jesus, M. E. F. (2019). Representações sociais de pessoas em situação de rua sobre morador de rua que usa drogas. Revista Baiana de Enfermagem33,

Ceolin, B., Terra, I. C., \& Carmona, R. (2020). População em situação de rua: estudo da realidade vivida. Humanidades em Perspectivas, 4(8).

Giovanella, L., Mendoza-Ruiz, A., Pilar, A. D. C. A., Rosa, M. C. D., Martins, G. B., Santos, I. S., \& Machado, C. V. (2018). Sistema universal de saúde e cobertura universal: desvendando pressupostos e estratégias. Ciência \& Saúde Coletiva, 23, 1763-1776.

Hamada, R. K. F., Alves, M. J. M., Hamada, H. H., Hamada, J. S. F., \& Valvassori, P. M. D. (2018). População em situação de rua: a questão da marginalização social e o papel do estado na garantia dos direitos humanos e do acesso aos serviços de saúde no Brasil. Revista de APS, 21(3).

Lima, M. E., menezes junior, A. D. S., \& brzezinski, I. (2017). Cidadania: sentidos e significados. In XIII Educere (congresso nacional de educação)Formação de professores: contextos, sentidos e práticas. Curitiba.

Lopes, H. P., \& Gonçalves, A. M. (2018). A política nacional de redução de danos: do paradigma da abstinência às ações de liberdade. Revista Pesquisas $e$ Práticas Psicossociais, 13(1), 1-15.

Magnin, C. (2021). Cidadania local e a volatilização do político examinadas através de exemplos de participação em propostas de planejamento urbano. Civitas-Revista de Ciências Sociais, 21, 172-185.

Mota, F. O., Fonseca, R. M. A. M., Santos, J. E. D., \& Gallassi, A. D. (2019). Aspectos do cuidado integral para as pessoas em situação de rua acompanhadas por serviço de saúde e assistência social: um olhar para e pela terapia ocupacional. Cadernos Brasileiros de Terapia Ocupacional , 27 , 806-816.

Nascimento, D. D. D. S. D. (2021). A dependência de substâncias psicoativas e o papel da família no cuidado ao usuário: fatores de risco e de proteção.

Oliveira, G. B., Selusnhaki, A. M., Higa, D. M., Araújo, J., dos Reis, T. C. M., \& dos Santos Azevêdo, A. V. Pessoas em situação de rua: revisão sistemática. Estudos Interdisciplinares em Psicologia, 11(2), 58.

Pio, D. N., Koopmans, F. F., de Araujo Faria, M. G., de Paula, H. C., \& Daher, D. V. (2020). Vulnerabilidade das pessoas em situação de rua e seus mecanismos de sobrevivência: revisão integrativa de literaturA. Epitaya E-books, 1(11), 161-171.

Rossi, C. C. S., \& Tucci, A. M. (2020). Acesso ao tratamento para dependentes de crack em situação de rua. Psicologia \& Sociedade, 32.

Santana, R. T. M., \& Mungo, E. L. L. (2021). O não reconhecimento do morador de rua como cidadão brasileiro. TCC-Direito.

Santos, J., Silva, S. X. O., Costa, T. S., Camboim, J. C. A., Bezerra, A. L. D., \& de Farias Camboim, F. E. (2021). Assistência de enfermagem na percepção dos usuários do Centro de Atenção Psicossocial Álcool e Drogas. Bioethics Archives, Management and Health, 1(1), 1-14.

Siqueira, D. F. D., Terra, M. G., Vieira, L. B., Mello, A. D. L., Moreschi, C., \& Soccol, K. L. S. (2018). Ações de cuidado aos familiares de usuários de substâncias psicoativas: intencionalidades / expectativas. Revista Brasileira de Enfermagem, 71, 2221-2228.

Soares Filho, W. (2017). Memória e representações sociais sobre drogas e redução de danos de usuários e equipe multiprofissional de um CAPS $A D$ (Doctoral dissertation, Dissertação de mestrado). Universidade Estadual do Sudoeste da Bahia, Vitória da Conquista, BA).

Taquette, S. R., \& Minayo, M. C. (2016). Análise de estudos qualitativos conduzidos por médicos publicados em periódicos científicos brasileiros entre 2004 e 2013. Physis: Revista de Saúde Coletiva, 26 , 417-434.

Thomé, C. Morar na rua x cidadania. Cadernos Jurídicos, São Paulo, ano, 20, 9-24.

Toigo, G. H. (2021). As relações familiares de dependentes químicos em situação de rua.

Venturi, V., dos Santos Maia, L. F., Sanches, A. M., \& Vasconcellos, C. (2021). Dependência química: saúde mental das pessoas em situação de rua. Revista Científica de Enfermagem-RECIEN, 11(33). 